\title{
PEMUTAKHIRAN PEMBELAJARAN BERBASIS PAPERLESS DI PROGRAM STUDI PENDIDIKAN BAHASA DAN SASTRA INDONESIA
}

\author{
Susandi, M.Pd. \\ susandi.ikipbudiutomo@gmail.com
}

Penggunaan paperless dalam pembelajaran dapat diterapkan dari hal yang sederhana dimulai dari presensi kelas, silabus, materi, media, model, tugas, dan evaluasi pembelajaran. Kebijakan paperless hadir sebagai bentuk jawaban atas keprihatinan terhadap isu permasalahan lingkungan serta tantangan pembelajaran di era teknologi informasi. Sumber daya dosen saat ini yang mayoritas masih berusia produktif yang memiliki komitmen serta kemauan kuat dalam menguasai teknologi informasi dalam pembelajaran merupakan modal besar institusi perguruan tinggi dalam memutakhirkan pembelajaran berbasis paperlees di Program Studi Pendidikan Bahasa dan Sastra Indonesia. Mahasiswa sebagai pengguna kebijakan juga harus berperan aktif dalam menyukseskan kebijakan tersebut. Perguruan Tinggi harus memberikan dukungan penuh secara bertahap upaya pemutakhiran sarana dan prasarana pendukung seperti televisi layar datar di setiap kelas, jaringan internet nirkabel, dan gawai bagi setiap mahasiswa dan dosen. Masyarakat dan pemerintah wajib memberikan dukungan dan apresiasi kepada Perguruan Tinggi yang memiliki komitmen dalam menerapkan kebijakan paperless. Kebijakan Paperless memiliki beberapa kelebihan di antaranya, efisiensi waktu dan biaya, ramah lingkungan, dan membuat manajemen dokumentasi dalam pembelajaran di Program Studi Pendidikan Bahasa dan Sastra Indonesia menjadi lebih baik.

Kata kunci: pemutakhiran, pembelajaran, paperless, bahasa dan sastra

\section{MODERNIZATION LEARNING BASED ON PAPERLESS IN INDONESIAN LANGUAGE AND LITERATURE EDUCATION STUDY PROGRAM}

The use of paperless in learning can be applied from simple things starting from class presences, syllabus, material, media, model, task, and learning evaluation. Paperless policy comes as a form of response to concerns about environmental issues and learning challenges in the information technology era. Currently, the majority of productive lecturers with strong commitment and strong will in mastering information technology in learning are big capital of higher education institution in updating paperlees based learning in Indonesian Language and Literature Education Study Program. Students as policy users must also play an active role in the success of the policy. Higher Education should provide full support gradually efforts to update supporting facilities and infrastructures such as flat-screen televisions in each class, wireless internet network, and devices for every student and lecturer. Society and government must provide support and appreciation to Higher Education who have commitment in applying paperless policy. Paperless Policy has several advantages including, time and cost efficiency, environmentally friendly, and make documentation management in learning in Indonesian Language and Literature Education Study Program better.

Keywords: modernization, learning, paperless, language and literature 


\section{PENDAHULUAN}

Kecepatan mendistribusikan informasi pembelajaran merupakan tolok ukur dalam persaingan di era informasi. Sebuah lembaga harus melaksanakan fungsi secara tepat. Oleh karena itu, paperless menjadi salah satu jawaban atas usaha tersebut.

Sebagai garda terdepan pengetahuan, lembaga pendidikan sudah seharusnya memahami pentingnya paperless dalam setiap kegiatannya. Penggunaan paperless ini dapat diterapkan dari hal sederhana seperti presensi kelas, silabus, materi, media, model, tugas, dan evaluasi pembelajaran. Paperless juga menjadi model baru teknologi yang efesiensi dan ramah lingkungan dan belum banyak diterapkan. Keberadaan paperless sebagai solusi belum banyak diterapkan pada lembaga pendidikan. "Dalam konteks lingkungan, paperless adalah langkah nyata mengurangi penggunaan pohon untuk kertas. Konsumsi kertas dunia telah tumbuh 400 persen dalam 40 tahun terakhir. Sekarang hampir 4 miliar pohon atau 35 persen dari total pohon yang ada dipotong di seluruh dunia dan digunakan dalam industri kertas di setiap benua .... Singkatnya, kertas ada di mana-mana." (Colby, 20111)

Sistem pembelajaran berbasis paperless berbentuk digital saat ini sangat penting untuk diterapkan di kelas, mengingat sarana dan prasarana teknologi yang tersedia saat ini sudah sangat mendukung untuk seminimal mungkin menggunakan kertas dan mendigitalisasi dokumen pembelajaran. Pengarsipan tanpa kertas bukan lagi mimpi masa depan, transisi telah dimulai.

Dokumen berbentuk digital tentu akan membutuhkan tempat yang sangat kecil dibanding dengan dokumen fisik yang berbentuk kertas. Dokumen pembelajaran yang mudah dan cepat dicari yang telah berbentuk digital dapat disimpan dalam perangkat keras yang dapat memuat ribuan atau bahkan jutaan dokumen. Penerapan konsep ini menjadi penting dalam membantu dunia pendidikan menuju teknologi yang modern.

Penerapan sisitem ini memiliki tantangan, yaitu kemampuan dosen dalam menerapkan pembelajaran yang menarik tanpa menggunakan kertas, khususnya di Prodi Pendidikan Bahasa dan Sastra Indonesia. Pembuatan bahan dan materi pembelajaran berbasis 
paperless akan memakan waktu yang lebih lama karena dosen harus mempelajari dan menguasai penggunaan dan penerapan sebuah atau beberapa aplikasi pembelajaran. Mahasiswa sebagai pengguna juga harus terbiasa dalam mengikuti proses dan metode pembelajaran berbasis paperless.

\section{PEMBAHASAN}

\section{Pengertian Paperless}

Secara umum paperless dimaknai sebagai segala bentuk kegiatan penyimpanan dokumen tanpa menggunakan kertas. Sejalan dengan itu, di dalam kamus Oxford (2018) dijelaskan bahwa "Paperless is Relating to or involving the storage or communication of information in electronic form, rather than on paper." Paperless tidak dimaknai sebagai penyimpanan dalam bentuk elektronik tetapi dia juga merupakan sebuah komunikasi elektronik bukan di atas kertas.

\section{Dasar Pembelajaran berbasis Paperless \\ Pelaksanaan paperless di} Indonesia sebenarnya telah diatur rapi dalam Undang-Undang maupun Intruksi Presiden. Landasan tersebut terdapat dalam Kominko, (2016), yaitu Undang-Undang No 11 Tahun 2008 tentang Informasi dan Transaksi Elektronik mencakup asas kepastian hukum, manfaat, kehati-hatian, iktikad baik, dan kebebasan memilih teknologi serta terdapat dalam Inpres RI No 3 tahun 2003 yang mencakup maksud, tujuan, kelemahan, strategi, dan upaya pengembangan SDM yang perlu dilakukan untuk mendukung $E$ government (Bappenas, 2009).

\section{Tujuan dan Manfaat Paperless}

Tujuan dari penggunaan paperless, yaitu mengurangi pemakaian kertas. Hal ini tidak bertujuan untuk meniadakan pemakaian kertas. Paperless tidak sama dengan bebas kertas. Dosen tetap menggunakan kertas di dalam kelas

Harpaz (dalam Stimpson 2004), menyebutkan keuntungan pendekatan paperless, yaitu (1) mengerjakan lebih banyak pekerjaan tanpa menambah sumber daya manusia, penggurangan biaya menyimpan dokumen, ruang kerja di kantor, gudang, biaya cetak, surat menyurat, dan lainnya, 3) informasi lebih cepat diakses dan lengkap. Dapat berbentuk self service, (4) data yang disimpan dalam bentuk daring diproteksi 
menggunakan enkripsi data. Akses dan pengawasan data dapat lebih terjamin.

Civitas Perguruan Tinggi peduli Paperless di Indonesia haruslah mulai dibentuk dengan menyiapkan berbagai panduan untuk mengurangi penggunaan kertas. Anaheim University di California menyatakan bahwa universitas pertama di dunia yang menggunakan konsep Paperless University dan mereka memiliki keinginan untuk meminta universitas lain segera bergabung untuk menerapkan hal tersebut serta menciptakan yang lebih baik melalui perbaikan lingkungan. Misi yang terdapat dalam laman History \& Mission Universitas Anaheim (2018) menyebutkan Universitas Anaheim membuat pendidikan tinggi agar dapat diakses oleh seluruh siswa yang di seluruh dunia. Hal ini dilakukan melalui studi online di kampus. Berdasarkan beberapa misi yang mereka turunkan, misi untuk mencapai visi paperless tahun 2020, yaitu (1) pemanfaatan teknologi baru dan handal, dan (2) penggunaan sumber daya pendidikan berbasis teknologi.

\section{Faktor Pendukung}

Ada beberapa hal yang harus diperhatikan dalam mengembangkan
Pembelajaran Bahasa dan Sastra Indonesia berbasis Paperless: Sumber daya dosen, (2) sarana pendukung, (3) sistem aplikasi, (3) visioner.

a) Sumber Daya Dosen

Sumber daya dosen yang mayoritas masih berusia produktif merupakan modal besar institusi dalam menerapkan pembelajaran Bahasa dan Sastra Indonesia berbasis paperlees. Komitmen serta kemauan kuat dalam menguasai teknologi informasi yang biasa melekat pada dosen muda merupakan anugerah terbesar sebuah institusi perguruan tinggi. Mahasiswa sebagai pengguna kebijakan juga harus berperan aktif dalam menyukseskan kebijakan tersebut.

b) Sarana Pendukung

Perguruan Tinggi sebagai pemangku kebijakan harus memberikan dukungan penuh secara bertahap upaya pemutakhiran sarana dan prasarana pendukung. Ketersediaan sarana yang diperlukan untuk mewujudkan kebijakan paperless. Tidak hanya terbatas pada kebijakan saja tetapi harus didukung oleh perangkat keras, infrastruktur jaringan, sumber daya manusia dengan keahlian IT sesuai, dana, dan forum komunikasi. 
Dukungan dan apresiasi masyarakat dan pemerintah kepada Perguruan Tinggi yang memiliki komitmen dalam menerapkan kebijakan paperless juga sangat dibutuhkan agar tujuan pembelajaran Bahasa dan Sastra Indonesia berbasis papaerless dapat terwujud sesuai dengan harapan.

c) Sistem Aplikasi

Dokumen daring yang tersimpan keamanan data dan kemudahan pemakaian. Aplikasi daring memberikan keamanan, kemudahan, dan kenyamanan, serta kecepatan kepada pengguna dalam memberikan layanan pada sistem teknologi informasi dan komunikasi. Aplikasi daring dapat menjangkau kepentingan dan kebutuhan manusia tanpa mengenal waktu, ruang, dan jarak tempuh.

d) Visioner

Seorang visioner diperlukan untuk dapat menjelaskan mengapa perlu menerapkan paperless. Sebagai bagian dari sebuah kesatuan, kemampuan seorang visioner dalam berkomunikasi sangat diperlukan. Harapan yang diinginkan, apa yang menjadi pesan dari tujuan kebijakan paperless dapat diterima oleh masyarakat sehingga masyarakat dapat mengikuti apa yang diinginkan oleh lembaga.

\section{Hasil Penelitian Pembelajaran berbasis Papaerless}

1) Mangen, B. R. W dan Kolbjorn, B. Penelitian yang berjudul Reading linear texts on paper versus computer screen: Effects on reading comprehension oleh Mangen, B R. W dan dan Kolbjorn, B merupakan penelitian komparatif. Penelitian ini menghasilkan bahwa siswa yang membaca teks dalam bentuk cetakan secara signifikan memperoleh nilai yang lebih rendah pada kegiatan tes membaca dibandingkan dengan siswa yang membaca teks secara digital.

2) Dwivedi, Sanjay K dan Anand Kumar

Penelitian berjudul Global Impacts and Challenges of Paperless Books, A Preliminary Study. St. John's University USA dalam International Journal of Business \& Social Science, volume. 3 Nomor. 11; June 2012 membandingkan perbedaan pandangan tentang penggunaan e-book dan buku cetakan. Hasil penelitian menunjukkan bahwa e-book selain dapat mengurangi biaya produksi juga dapat dijadikan 
sebagai solusi untuk melindungi lingkungan secara global. Pengurangan bahan bahan baku ini dapat meminimalkan penebangan pohon. Dengan demikian, hutan tanaman penghasil kayu dapat dipertahankan sebagai paru-paru bumi.

3) Tiwari, Mohit dan Seema Syah

$$
\text { Penelitian ini berjudul }
$$
Networking of Paperless Offices in Technical Institutes of India (2010). Penelitian ini menggunakan studi kasus pada dua Perguruan Tinggi di India. Survei berbasis angket digunakan terhadap mahasiswa, karyawan, dan pimpinan untuk menilai persepsi sivitas akdemika tersebut terhadap perubahan tradisi sistem pencetakan ke dalam bentuk teknologi informasi dan komunikasi. Hasil penelitian menunjukkan bahwa terdapat peningkatan terhadap penggunaan teknologi informasi dan komunikasi dengan variasi bidang manajemen.

Hal inilah yang menjadi dasar penerapan pembelajaran bahasa dan sastra Indonesia berbasis paperless. Hampir semua sivitas akademika merasa nyaman dengan menggunakan kebijakan paperless. Paperless memberi suasana baru dalam pembelajaran di era digital.

\section{Aplikasi Pendukung Pembelajaran} Bahasa dan Sastra Indonesia Berbasis Paperless

Kebijakan Paperless berjalan dengan baik, maka dibutuhkan beberapa aplikasi (perangkat lunak pendukung), yaitu.

1) Aplikasi google drive

Google drive merupakan aplikasi penyimpanan data yang bisa digunakan dimana saja menggunakan komputer, laptop, ponsel yang terhubung jaringan internet. Google drive menyediakan penyimpanan gratis 15 GB dan digunakan untuk penyimpanan dan untuk berbagi dokumen serta memudahkan untuk mengedit dokumen.

2) In-Class

Aplikasi ini digunakan dalam mengatur jadwal belajar agar lebih mudah. Aplikasi ini dapat mencatat materi penting dan mengerjakan tugas yang dikirim melalui e-mail ataupun berbagi melalui Facebook.

3) Cram

Aplikasi cram merupakan aplikasi yang mendukung quiz atau exam online, peserta didik langsung mengetahui nilai yang diperoleh setelah selesai mengerjakannya. Hal ini 
sangat menarik untuk segera mengetahui nilai.

4) Prezi

Prezi hadir sebagai perangkat lunak untuk membuat presentasi pembelajaran tersusun dalam sebuah canvas tanpa batas. Prezi menawarkan fitur zoom-in--zoom-out ketika terjadi perpindahan dari masing-masing frame. Sehingga pergerakan perpindahan frame akan menyerupai gerakan pada video.

\section{5) Adobe Flash Profesional}

Perangkat lunak pembuat vector plus animasi gambar bergerak hingga efek yang menarik. Rekomended untuk merancang media pembelajaran interaktif konten visual.

6) Windows Movie Maker

Perangkat lunak satu ini merupakan software bawaan Microsoft untuk pembuatan video silde sampai editing video. Sangat mudah untuk digunakan. Sehingga akan memudahkan guru untuk membuat suatu media pembelajaran interaktif audiovisual.

7) Whatsapp Messenger

Pemanfaatan whatsapp sebagai salah satu paperless memiliki keuntungan, yaitu tetap berjalannya proses pembelajaran meskipun tanpa kehadiran dosen di kelas. Materi pelajaran dalam satu semester tetap dapat dijalankan walau tanpa tatap muka. Peserta didik dapat membuat grup chating lalu presentasi di kelas. Kelompok lain dapat merekam presentasi dan dikirim kepada guru yang tidak dapat hadir menggunakan whatsapp messenger. Dosen dapat melakukan koreksi jika ada kesalahan pada materi.

8) Edmodo

Edmodo merupakan platform pembelajaran yang dapat digunakan dengan aman oleh peserta didik dan guru. Edmodo merupakan aplikasi berbasis sosial media. Edmodo memiliki kemiripan dengan facebook hanya saja lebih bersifat edukatif dan lebih banyak digunakan untuk kepentingan dunia pendidikan. Edmodo memiliki banyak fitur yang dapat digunakan untuk pelaksanaan pembelajaran. Fitur-fitur tersebut dapat dimanfaatkan sesuai dengan kebutuhan dosen dan mahasiswa. Fitur-fitur yang ada pada edmodo antara lain grup, perpustakaan, catatan, penugasan, pengumuman, dan lain sebagainya. Sebagai sebuah aplikasi, edmodo memiliki kelebihan sebagai berikut. (1) Compatibility. Edmodo mendukung 
preview berbagai jenis format file seperti: pdf, pptx, html,swf dan sebagainya (2) User Interface. Mengadaptasi tampilan seperti facebook, secara sederhana edmodo relatif mudah untuk digunakan bahkan untuk pemula sekalipun. (3) Aplikasi. Edmodo dapat diakses menggunakan PC (laptop/desktop) dan gadget berbasis Android OS.

\section{9) Google Classroom}

Google Classroom merupakan rangkaian tools produktivitas yang gratis dari Google, yaitu Gmail, Drive, dan Docs, menyediakan Google Apps for Education. Classroom dirancang untuk membantu membuat dan mengumpulkan tugas tanpa menggunakan kertas. Menghemat waktu dosen seperti kemampuan untuk membuat salinan Google Docs secara otomatis bagi mahasiswa. Classroom dapat membuat folder Drive untuk setiap tugas dari mahasiswa, agar semuanya tetap teratur. Aplikasi pendukung google classroom meliputi

a) GoGuardian Teacher

\begin{tabular}{lrr}
\multicolumn{2}{c}{ GoGuardian } & Teacher \\
memungkinkan & pengajar \\
menduplikasikan & kelas yang telah \\
disiapkan di & Classroom, \\
menyinkronkan pendaftaran siswa,
\end{tabular}

periode kelas, dan mata pelajaran di semua platform. Siswa dan pengajar akan mendapatkan lebih banyak manfaat dari Chromebook dengan penyiapan dan penggunaan yang lebih sederhana.

b) Additio App

Additio App merupakan suite produktivitas bagi pengajar yang berfungsi untuk mengelola pekerjaan dan menghubungi siswa serta keluarga secara efisien. Aplikasi tersebut menawarkan berbagai macam fitur yang bermanfaat, seperti buku nilai dan perencana kegiatan belajar mengajar yang dapat diandalkan.

c) Aeries

Dosen dapat menautkan atau membuat kelas Google Classroom baru berdasarkan kelas Aeries dan mengimpor nilai ke buku nilai Aeries.

d) Alma

Alma adalah Sistem Informasi Siswa pertama yang terintegrasi langsung dengan Google Classroom. Dengan integrasi ini, pengajar dapat menyinkronkan tugas dan nilai, dan tim teknis dapat membuat dan mengelola kelas Google Classroom secara massal. 
e) Little SIS for Classroom

Little SIS for Classroom secara otomatis membuat kelas di Google Classroom dan menyinkronkan daftar nama mahasiswa kelas dari informasi mahasiswa yang diekspor, sehingga mempermudah pengelola untuk menerapkan dan mengelola Google Classroom secara massal.

f) SalamanderSoft Active Directory

SalamanderSoft Active Directory akan otomatis membuat dan mengelola kelas-kelas di Google Classroom secara langsung dari sistem pengelolaan, termasuk wali dan jadwal kalender.

g) Schoolrunner

Schoolrunner adalah fitur untuk analisis data yang menggabungkan wawasan akademik dan budaya dalam 1 sistem yang intuitif. Dengan integrasi ini, pengajar dapat memuat nilai siswa dari Classroom langsung ke buku nilai Schoolrunner.

h) Sycamore

Sycamore menyinkronkan daftar nama siswa kelas, tugas, lampiran, dan nilai ke buku nilai Sycamore bagi pengajar untuk penyusunan laporan.

10) Moodle

Moodle merupakan salah satu aplikasi yang dapat digunakan oleh peseerta didik dan guru. Aplikasi inin memiliki kelebihan yang tidak ada di Edmodo. Kelebihan itu terletak dalam hal Administrative tools. Moodle memberikan fasilitas dalam memfasilitasi proses, media serta administrasi pembelajaran. Moodle menawarkan banyak plugin dan module yang dapat disesuaikan dengan kebutuhan seperti kehadiran, chatting, video conference menggunakan big blue button. keunggulan Moodle karena sifatnya yang terbuka/open source. Hal ini dapat digunakan untuk mengembangkan program yang ada dan disesuaikan dengan kebutuhan. Moodle dapat diakses secara daring dengan self-hosted atau free hosting, dan dapat diakses melalui jaringan lokal dari server kampus secara luring. pengaksesannya tidak bergantung pada koneksi internet. Hal ini memudahkan pengguna mengelola data-data. Moodle memfasilitasi hampir semua kebutuhan terhadap proses pembelajaran baik activity, resource maupun assessm ent.

Penerapan Pembelajaran Bahasa dan Sastra Indonesia Berbasis Paperless 
Selain

mempersiapkan

pengetahuan penggunaan berbagai macam aplikasi tersebut kepada mahasiswa, mahasiswa juga harus dibekali sarana pendukung seperti ponsel pintar (minimal berbasis android) yang spesifikasinya mendukung untuk pembelajaran berbasis paperless, jaringan wireless, internet, dan juga televisi layar datar yang bisa terkoneksi dengan internet. Persiapan yang dilakukan sebelum memulai sistem pembelajaran berbasis paperless.

1) Pengenalan, pembuatan, dan penggunaan Aplikasi

Peserta didik harus diperkenalkan terlebih dahulu tentang ponsel pintar, karena sebagian besar mahasiswa belum terbiasa menggunakan ponsel pintar untuk pembelajaran paperless. Mahasiswa diberikan pelatihan mulai dari perkenalan ponsel pintar hingga pengoprasian dasar ponsel tersebut dan pengenalan tentang apa itu paperless. Dengan adanya latihan tentang paperless, diharapkan nantinya mahasiswa tidak canggung mengikuti pembelajaran berbasis paperless ketika telah dimulai. Mahasiswa tidak lagi akan bertanya bagaimana cara untuk mengoperasikan ponsel pintar mereka .
Adapun materi pengenalan awal yang dapat menjadi rujukan tentang penggunaan ponsel pintar meliputi:

a) HOT (How To)

HOT berisikan materi pengenalan dasar ponsel pintar. Peserta latihan diberikan informasi tentang apa saja yang ada dan fungsifitur yang ada di ponsel pintar mereka. Pengetahuan tentang apa saja yang menggantikan fungsi buku yang mendukung pembelajaran paperless

b) HOM (How to Make)

Kegiatan HOM ini berkaitan dengan materi tentang ekplorasi Play Store, membuat E-mail, install aplikasi, remove aplikasi dan hal-hal lain.

c) $\operatorname{HOS}$ (How to Use)

Training bernama HOS berisikan materi tentang tips $\&$ trik dalam ponsel android, peserta diberikan tugas untuk mencari tahu tentang tips dan trik ponsel pintar android dan fungsi-fungsi tools. Hal ini bertujuan agar para peserta didik lebih mengenal perangkat.

2) Praktik Penggunaan Paperless dalam Pembelajaran

Selanjutnya latihan persiapan terhadap para dosen yang nantinya menjadi motivator sekaligus fasilitator di kelas pada saat perkuliahan 
berlangsung. Sistem pembelajaran paperless menuntut dosen menyusun langkah mengajar yang lebih menarik. Dosen perlu mendapat pelatihan yang hampir sama dengan mahasiswa. Perlu diberikan pengarahan khusus tentang tujuan utama pembelajaran berbasis paperless, memberikan pemahaman tentang apa yang ingin dicapai oleh sistem pembelajaran ini. Aplikasi yang terinstal di dapat dimanfaatkandalam mendukung pembelajaran paperless agar berjalan dengan baik. Tujuan utama pembelajaran paperless pun tercapai. Dosen wajib membuat presentasi untuk proyek akhir. Presentasi berisi simulasi gambaran berlangsungnya perkuliahan. Setiap dosen mampu mengekplorasi minimal satu aplikasi penting yang menjadi rencana awal penerapan pembelajaran berbasis paperless di kelas.

3) Pembentukan Komunitas Paperless

$$
\text { Pembentukan komunitas }
$$

paperless di dalam sebuah program studi mutlak diperlukan. Hal tersebut dilakukan agar komunikasi dan diskusi tetang pembelajaran berbasis paperless ini dapat lebih intens. Fungsi komunitas ini untuk mendiskusikan persiapan yang dilakukan, aplikasi yang akan digunakan, dan teknis pelaksanaannya. Komunitas ini dapat mengungkapkan ide penting yang diharapkan dapat memecahkan permasalahan menuju perubahan sistem pembelajaran berbasis paperless, khususnya di prodi dan di perguruan tinggi pada umumnya.

\section{KESIMPULAN}

Kebijakan Paperless memiliki beberapa kelebihan di antaranya, efisiensi waktu dan biaya, ramah lingkungan, dan membuat manajemen dokumentasi dalam pembelajaran Bahasa dan Sastra Indonesia menjadi lebih baik. Pelaksanaan paperless di Indonesia diatur dalam UndangUndang Nomor 11 Tahun 2008 dan Inpres RI No 3 tahun 2003.

Tujuan kebijakan penggunaan paperless, yaitu mengurangi pemakaian kertas. Keuntungan dalam penggunaan Pendekatan paperless sebagai berikut, (1) mengerjakan lebih banyak pekerjaan tanpa menambah sumber daya manusia, (2) Mengurangi biaya, biaya menyimpan dokumen, ruang kerja dalam kantor, gudang, biaya cetak, surat menyurat dan lainnya, (3) informasi mudah diakses dan lengkap, (4) data yang sensitif tidak tersimpan dalam bentuk kertas tetapi disimpan dalam bentuk daring 
yang diproteksi menggunakan enkripsi data.

Ada beberapa hal yang harus diperhatikan dalam mengembangkan Pembelajaran Bahasa dan Sastra Indonesia berbasis Paperless: (1) Sumber daya dosen, (2) sarana pendukung, (3) sistem aplikasi, (3) visioner. Beberapa aplikasi pendukung dalam paperless antara lain, (1) aplikasi Google Drive, (2) In-Class, (3) Cram, (4) Prezi, (5) Adobe Flash Profesional, (6) Windows Movie Maker, (7) Whatsapp Messenger, (8) Edmodo, (9) Google Classroom, (10) Moodle.

Persiapan yang harus dilakukan sebelum memulai memasuki sistem pembelajaran berbasis paperless antara lain, (1) Pengenalan, pembuatan, dan penggunaan aplikasi. (2) Praktik penggunaan paperless dalam Pembelajaran. (3) Pembentukan komunitas paperless.

\section{DAFTAR PUSTAKA}

Anaheim University. 2018. History and Mission.

https://www.anaheim.edu/ aboutanaheim-

university/background.html.

Diakses tanggal 20 Juli 2018.

Bappenas. 2009. Instruksi Presiden Nomor 3 Tahun 2003 Tentang Kebijakan \& Strategi Nasional
Pengembangan e - Governmet. https://www.bappenas.go.id/id/dat a-dan-informasi-utama/produkhukum-peraturanperundangan/inpres/inpres-no3tahun-2003-tentang-kebijakandan-strategi-nasionalpengembangan-e-governmet/. Diakses tanggal 20 Juli 2018.

Colby, Susan. 2011. Paper Chase. http://www.ecology.com/2011/09/ 10/ paper-chase/. Diakses tanggal 20 Juli 2018.

Dwivedi, Sanjay K dan Anand Kumar. 2013. Global Impacts and Challenges of Paperless Books: A Preliminary Study. Business and Social Science.volome. 3 Nomor. 11, June 2013.

Kominko. 2016. Revisi UndangUndang No. 11 Tahun 2008 tentang Informasi dan Transaksi Elektronik.

https://www.kominfo.go.id/content / detail/8434/siaran-pers-no83hmkominfo112016-tentangrevisi-uu-no-11-tahun-2008mengenai-informasi-dan-transaksielektronik/0/siaran_pers. Diakses tanggal 20 Juli 2018.

Mangen, A; Bente R. Walgermo, K. B. 2013. Reading linear texts on paper versus computer screen: Effects on reading comprehension. Educational Research. hlm 61-68.

Oxforddictionaries. (2018). English Oxford Living Dictionaries. https://en.oxforddictionaries.com/d efinition/paperless. Diakses tanggal 20 Juli 2018.

Stimpson, Jeff. 2004. The Nitty-Gritty of Going Paperless. The Practical 


\author{
Accountant. \\ http://www.webcpa.com/current_is \\ sue.cfm?pub=prc. Diakses tanggal \\ 20 Juli 2018.
}

Tiwari, Mohit dan Seema Syah. 2010. Networking of Paperless Offices in Technical Institutes of India. Computer Science and Network Security. vol.10 no.3, hlm. 171181. 